\title{
Epithelial-Mesenchymal Transitions - New Insights into Signaling, Development and Pathogenesis
}

This 2nd special edition of Cells Tissues Organs on epithelial-mesenchymal transitions (EMT) stems from the 2nd International Conference on EMT, which was convened by Shoukat Dedhar and Raghu Kalluri on October 1-3, 2005, in Vancouver, B.C., Canada. EMT - the transformation of epithelial cells which are usually arranged in a coherent layer and sessile, into more individualistic and motile cells, mesenchymal cells - is well recognized as an important primary mechanism in embryogenesis for remodeling tissues, as is the reverse transition. This has obvious implications in numerous pathophysiologies, and in particular EMT has emerged as an important feature of fibrosis in a growing number of organ types. It is now clear that about a third of the fibroblasts in the setting of organ fibrosis are likely derived from the epithelium. Cancer EMT remains topical, and although EMT has been reported in many cancer studies, this meeting was held against a backdrop of controversy in the cancer community as to the prevalence of EMT in clinical scenarios [Tarin et al.: Cancer Res 2005;65:5996-6000; Thompson et al.: Cancer Res 2005;65:5991-5995]. Being the 2nd International EMT Meeting, the sessions focused on new developments and controversies, and in-depth analysis of major signaling pathways recognized to regulate EMT across different platforms. The domains of development, pathology and cancer, brought together around EMT at the inaugural meeting in 2003, were again well represented. The future goals for EMT research include identifying EMT targets for possible therapeutic intervention.
This diversity of EMT studies and the emergence of new concepts and regulatory processes are reflected in the chapters assembled for this volume. The articles are roughly divided into different 'sections'. The first covers new EMT model systems, and the second and third sections scrutinize EMT pathways, in an attempt to identify specific transducers and effectors. Major advances are reported in identifying new model systems, transcriptional regulators (including chromatin structure and micro RNA), specific signaling pathways, and effector molecules. A separate section examines the role and regulation of the TGF- $\beta$ signaling pathways in great detail in distinct models. Several microarray analysis approaches are reported, also targeting the EMT process in distinct models. In the following articles, Snail signaling and targets are carefully explored in several systems. The last sections cover in vivo occurrences of EMT and pathological variations, including fibrosis.

In this special issue, recent developments in the EMT field are reviewed with some exclusive results, including the first localizations of Snail proteins in human cancers. New concepts are consolidated including partial EMT, resulting in a metastable phenotype seen in cancer systems over a number of articles, and the reversed EMT or mesenchymal-epithelial transition reported in particular in a model of bladder cancer progression. This special issue also includes the first therapeutic approaches specifically targeting the EMT process. We tried to be inclusive in inviting contributions to this issue, and this resulted in the 30 different articles and reviews assembled here.

\section{KARGER}

Fax +4161306 1234

E-Mail karger@karger.ch

www.karger.com
(C) 2007 S. Karger AG, Basel

$1422-6405 / 07 / 1853-0005 \$ 23.50 / 0$

Accessible online at: www.karger.com/cto 
These provide an in-depth view of the topics covered at the meeting, many of which were also summarized at the time in a topical mini-review [Lee et al.: J Cell Biol 2006; 172:973-981].

The success of this second meeting and of TEMTIA The EMT International Association (http://www.mtci. com.au/temtia.html), which was formed in conjunction with the first meeting - is testament to the continued recognition of EMT as an important pathway in many disciplines. The conference would not have been possible without the generous support of an NIH (USA) R13 Conference Grant representing numerous Institutes [AR, CA, DE, DK, and HD (primary sponsor); NIH/NICHD 1-R13-CA117785-01], and grants from the Canadian Institutes for Health Research (CIHR) and the National Cancer Institute of Canada (NCIC).

The meeting was guided by an international committee chaired by Professor Shoukat Dedhar (UBC, Canada) and including Mina Bissell (LBNL, USA), Elizabeth Hay
(Harvard, USA), Kohei Miyazono (Japan), Suresh Mohla (NCI, USA), Donald Newgreen (Melbourne, Australia), Pierre Savagner (Montpellier, France), Jean-Paul Thiery (Paris, France), Erik Thompson (Melbourne, Australia) and Robert Weinberg (Whitehead Institute, USA). As this issue goes to press, plans are already well in hand for the 3rd International EMT Meeting which will be structured as an EMBO Workshop, co-organized by TEMTIA and the Marie-Curie Epiplastcarcinoma RTN network, September 10-12, 2007, at Larisha Palace, Cracow, Poland. The meeting will be co-chaired by Pierre Savagner, Aristidis Moustakis, Antonio Garcia de Herreros and Amparo Cano. We look forward to seeing you there for a further update on these transitions between epithelial and mesenchymal states.

Erik W. Thompson, Melbourne, Vic. Pierre Savagner, Montpellier Shoukat Dedhar, Vancouver, B.C. Raghu Kalluri, Boston, Mass.

\section{Editorial Note}

The editors are pleased to continue, with this volume, a series of Special Topic Issues on EMT. This journal has pioneered publishing on EMT already at a time when this was still considered a very new and debated concept, and the first two Special Topic Issues on EMT appeared when the journal was still published under the name Acta Anatomica. Cells Tissues Organs plans to maintain one of its focuses on this exciting and rapidly expanding field of research.

H.-W. Denker, Essen

Previous Special Topic Issues on EMT:

- Acta Anatomica Vol. 154, No. 1, 1995: Epithelial-Mesenchymal Transitions. Part I. Guest Editor: D.F. Newgreen, Melbourne

- Acta Anatomica Vol. 156, No. 3, 1996: Epithelial-Mesenchymal Transitions. Part II. Guest Editor: D.F. Newgreen, Melbourne

- Cells Tissues Organs Vol. 179, No. 1-2, 2005: Recent Progress in Epithelial-Mesenchymal Transitions. Development - Cancer - Pathology.

Guest Editors: D.F. Newgreen and E.W. Thompson, Melbourne 